\title{
Pengaruh Tari Ayam Modifikasi Terhadap Perkembangan Motorik Kasar Anak di Taman Kanak-Kanak Jabal Rahmah Padang
}

\author{
Henifo Oktari \\ Serli Marlina \\ Program Studi Pendidikan Guru Pendidikan Anak Usia Dini Fakultas Ilmu Pendidikan \\ Universitas Negeri Padang \\ Email: henifooktari@yahoo.com
}

Received March 2019, Accepted April 2019, Published April 2019

\begin{abstract}
This research begins with the challenge of implementing gross motor development that has not supported coordinated body movement. This study aims to find out how to change the gross motoric skills of children in Jabal Rahmah Padang Kindergarten. This study uses quantitative compilation of Quasi Eksperiments. The study population was all children in Jabal Rahmah Padang Kindergarten, and the Purvosive Sampling sampling technique, namely classes B1 and B2 each of which could be contacted by 10 children. The technique of collecting data using a test consists of 5 points of approval and a data collection tool using the approving sheet. Then the data processed by the difference test ( $t$-test). Based on the data analysis, the average experimental class test is 85 and $S D$ is 8.06 while the control class 77 and $S D$ is 6,78 in the hypothesis testing obtained by tcount $(2,279$ and ttable of 2,100 at the real level $=0,05$ and $d k=18$. It can be concluded that the use of modified chicken dance opposes the gross motor development of children in Jabal Rahmah Padang Kindergarten 2018/2019.
\end{abstract}

Keywords: Modified Chicken Dance, Gross Motor Skills, Body Movement

\begin{abstract}
Abstrak: Penelitian ini berawal dari kenyataan pelaksanaan pengembangan motorik kasar yaitu anak belum mampu melakukan gerakan tubuh secara terkoordinasi. Penelitian ini bertujuan untukmengetahui pengaruh tari ayam modifikasi terhadap perkembangan motorik kasar anak di Taman Kanak-Kanak Jabal Rahmah Padang. Penelitian ini menggunakan pendekatan kuantitatif yang berbentuk Quasi Eksperiment. Populasi penelitian adalah seluruh anak diTaman Kanak-Kanak Jabal Rahmah Padang, dan teknik pengambilan sampelnya Purvosive Sampling, yaitu kelas B1 dan B2 masing-masingnya berjumlah 10 orang anak. Teknik pengumpulan data menggunakan tes, berupa pernyataan sebanyak 5 butir pernyataan dan alat pengumpulan data digunakan lembaran pernyataan. Kemudian data diolah dengan uji perbedaan ( $t$-test). Berdasarkan analisis data, diperoleh rata-rata tes kelas eksperimen adalah 85 dan SD sebesar 8,06 sedangkan kelas kontrol adalah 77 dan SD sebesar 6,78 pada pengujian hipotesis diperoleh $t_{\text {hitung }}$ sebesar $\left(2,279\right.$ dan $t_{\text {tabel }}$ sebesar 2,100 pada taraf nyata $\alpha=0,05 \mathrm{dan} \mathrm{dk}=18$. Maka dapat disimpulkan pengunaan tari ayam modifikasi berpengaruh terhadap perkembangan motorik kasar anak di Taman Kanak-Kanak Jabal Rahmah Padang tahun ajaran 2018/2019.
\end{abstract}

Kata Kunci : Tari Ayam Modifikasi, Kemampuan Motorik Kasar, Gerakan Tubuh

\section{PENDAHULUAN}

Anak usia dini merupakan sosok yang polos sekaligus penuh dengan potensi yang ada dalam dirinya, dan memiliki karakteristik yang sangat unik, hal ini yang sering kenal dengan masa Golden Age atau masa keemasan. Marlina (2014) anak merupakan individu yang sedang mengalami suatu proses perkembangan yang sangat pesat dan sangat fundamental. Hal ini memastikan kualitas hidup di masa yang akan datang.

Pendidikan anak usia dini memberikan pengaruh sangat luar biasa terhadap perkembangan anak karena meletakkan dasar perkembangan selanjutnya. Ketika anak dewasa, pendidikan di usia dini akan memberikan bekas yang mendalam dan sangat mempengaruhi sikap, prilaku dan kecerdasannya ( Nurhafiza \& Azlina, 2015)

Menstimulasi perkembangan anak usia dini itu sangat penting dilakukan sehingga dapat membimbing, mengasah, dan pemberian kegiatan yang akan menghasilkan kemampuan serta berbagai keterampilan dalam pendidikan anak usia dini. Ada beberapa aspek dalam pendidikan anak usia dini seperti: nilai agama dan moral, fisik motorik terbagi 2 yaitu motorik kasar dan motorik halus, bahasa, kognitif, dan sosial emosional. Keterampilan dasar yang 
Volume 6, Nomor 1, April 2019, hal 29 - 34

harus dimiliki anak merupakan perkembangan fisik motorik.

Bidang kemampuan dasar fisik, terbagi 2 motorik kasar dan motorik halus. Fisik yang diambil dalam pembahasan ini adalah motorik kasar. Kegiatan fisik yang selalu melibatkan otot-otot besar anak sehingga anak mampu dalam menggerakkan tubuhnya. Mursid (2015:12) untuk melatih gerakan jasmani berupa koordinasi gerakan tubuh contohnya anak merangkak, berjinjit, bergantung di tiang, melempar bola, dan menjaga keseimbangan dalam bermain papan titian semua ini merupakan kegiatan motorik kasar.

Kecerdasan kinestetik merupakan kelebihan yang dimiliki seseorang lebih dari yang lainnya dalam mengelolah gerakan motorik tubuhnya. Anak yang menonjol dalam kecerdasan ini selalu mengekspresikan dirinya melalui gerakan-gerakan tubuh (Nurhafizah, 2011).

Hal ini sebagaimana dikemukakan oleh Gallahue dalam (Mirantika 2017: 3) kegiatan menari, permainan, olahraga, dan senam merupakan kegiatan dalam mengembangkan pola-pola gerak karena termasuk ke dalam pengembangan motorik. Sehingga kebutuhan dasar anak terarah kaarah yang benar.

Manusia merupakan makhluk yang paling sempurna diciptakan Tuhan. Salah satu keistimewaannya adalah manusia itu dilengkapi dengan akal dan fikiran. Aktivitasaktivitas manusia dicetuskan menerusi akal, fikiran, cipta, rasa, dan karsa, menghasilkan sebuah karya seni yang mengisi kebudayaan. Hasil karya tersebut menjadi kebanggaan bagi si pencipta sehingga sentiasa dijaga kelestariannya. (Indra Yeni, 2012)

Gerakan yang indah yang lahir sesuai irama adalah tari. Suryodinigrat dalam (Astuti 2015: 5) tari merupakan gerakan yang lahir dari seluruhan anggota tubuh yang yang selaras dengan alunan musik dan memberikan makna tertentu disetiap gerakan.

Tari dikelompokkan menjadi tiga jenis, yaitu : 1) jenis tari berdasarkan pola garapan terbagi dua yaitu, tari tradisional dan tari kreasi baru; 2) jenis tari berdasarkan koreografi dibagi tiga yaitu, tari tunggal, tari berpasangan, dan tari kelompok; 3) jenis tari berdasarkan tema dibedakan menjadi dua,yaitu tari dramatik dan tari non dramatik. (Mulyani, 2016).

Gerakan yang diajarkan pada anak selalu berkaitan dengan hal berikut :

1) Waktu, waktu yang berkaitan dengan cepat/lambat; 2) Beban, Gerakan dapat diberikan dalam bentuk gerakan yang berat, ringan, atau sedang; 3) Ruang, Gerakan juga berkaitan dengan ruang, yaitu sejauh mana gerakan tubuh itu menggunakan ruang dalam pelaksanaanya; 4) Alur, Gerak adalah sesuatu yang berkesinambungan yang mengalir dari gerak tertentu ke gerak lainnya (Suryana, 2016)

Cirikhas kegiatan gerak berirama ana $\mathrm{k}$-anak ialah kebebasan besekspresi melalui gerakan dengan iringan musik, anak- anak melakukan gerakan tubuh sesuai dengan keinginan sendiri. Disini anak mengeluarkan kemampuan yang dia miliki dengan bergaya sesuai ekspresi diri sendiri.

Modifikasi tari adalah kegiatan mengubah, menambah, mempercantik gerakan tari sehingga lebih enak dipandang. Mengubah ruang, tenaga dan arah hadap termasuk kedalam memodifikasi gerak yang kita rangkai sendiri sehingga menghasilkan sebuah tari. Harry dalam (Gusti 2018:29).

Salah satu stimulasi yang bisa dilakukan guna memberikan rangsangan terhadap kemampuan motorik kasar anak yaitu dengan menggunakan tari ayam modifikasi. Menurut Masganti (2017: 8) animal dance tari yang sangat cocok dengan karakteristik anak usia dini yaitu tarian yang sederhana yang mudah dipahami anak dengan musik kegembiraan sehingga anak tertarik dan anak bersemangat dalam menggerakkan anggota tubuhnya.

\section{METODE}

Dari permasalahan yang diteliti oleh peneliti merupakan jenis penelitian kuantitatif dengan metode eksperimen dengan jenis eksperimen semu (quasy eksperiment). Sugiyono (2017: 72) "kondisi yang terkendalikan dalam mencari pengaruh pada perlakuan tertentu dapat dikatakan sebagai metode penelitian eksperimen".

Pada kelas eksperimen diberikan perlakuan dari kegiatan tari ayam modifikasi terhadap kemampuan motorik kasar anak. Saat penelitian ini yang mengajar dikelas eksperimen peneliti sendiri, sedangkan kelas 
kontrol diberikan perlakuan senam, pada penelitian yang mengajar dikelas kontrol merupakan guru kelas.

Populasi pada penelitian ini merupakan murid taman kanak-kanak jabal rahmah padang. Taman kanak-kanak dikepalai oleh ibuk Murni, S.Pd. Teknik pengambilan sampel pada penelitian ini purposive sampling. Anak kelas B1 dan B2 merupakan sampel. Yaitu kelas B1 merupakan kelas (eksperimen) dan B2 merupakan kelas (kontrol). Pada kelas B1 sampelnya 10 orang dan pada kelas B2 10 orang. Dalam penelitian ini peneliti menggunakan instrumen penilaian dengan menggunakan rating scale.

Teknik analisis data dalam penelitian ini adalah membandingkan nilai rata-rata antara kelas eksperimen dengan kelas kontrol, sehingga terbukti dengan uji-t (t-test), sebelum melakukan uji-t (t-test), yang pertama dilakukan uji normalitas dan uji homogenitas. Sebelum dilakukan analisis perbedaan, penting dilakukan uji normalitas dengan uji liliefors, dan uji homogenitas dengan uji Barlett.

\section{HASIL DAN PEMBAHASAN}

\section{Hasil}

Pada penelitian yang dilaksanakan melibatkan 5 item instrumen pernyataan dalam kemampuan motorik kasar anak. 1) anak mampu menirukan gerakan ayam mencari makan 2) Anak mampu bergerak menirukan gerakan ayam mengepakkan sayapnya 3) Anak mampu mengerakkan tangannya sambil berputar 4) Anak mampu meloncat ke kiri dan ke kanan dengan tangan membentuk paru 5) Anak mampu menggerakkan tangannya seperti ayam terbang.

Tabel 1 berikut merupakan rekapitulasi hasil pre-test. Bersadarkan tabel 1 berikut maka diperoleh hasil pretest lebih tinggi pada kelas eksperimen (B1) dibandingkan dengan kelas kontrol (B2). Pada tabel 2 berikut menyajikan hasil rekapitulasi dari post-tets.
Tabel 1. Rekapitulasi Hasil Pre-Test Kemampuan Motorik Kasar Anak Di Kelas Eksperimen Melalui Tari Ayam Modifikasi dan Kontrol Melalui Senam

\begin{tabular}{lcc}
\hline \multicolumn{1}{c}{ Variabel } & \multicolumn{2}{c}{ Pembelajaran } \\
& Eksperimen 1 & Kontrol 1 \\
\cline { 2 - 3 } N & 10 & 10 \\
\hline Nilai Tertinggi & 80 & 70 \\
& & 50 \\
\hline Nilai Terendah & 55 & 595 \\
\hline Jumlah Nilai & 645 & \\
\hline Median & & 62,5 \\
& 60,5 & 59,5 \\
\hline Rata-Rata & 64,5 & 6,85 \\
\hline SD & 7,34 & 46,92 \\
\hline SD & & \\
\hline
\end{tabular}

Tabel 2. Rekapitulasi Hasil Post-Test Kemampuan Motorik Kasar Anak Di Kelas Eksperimen Dan Kontrol

\begin{tabular}{lcc}
\hline \multicolumn{1}{c}{ Variabel } & \multicolumn{2}{c}{ Pembelajaran } \\
\cline { 2 - 3 } & Eksperimen 1 & Kontrol 1 \\
\hline Nilai Tertinggi & 10 & 10 \\
\hline Nilai Terendah & 95 & 85 \\
& & \\
\hline Jumlah Nilai & 80 & 65 \\
\hline Median & 850 & 770 \\
\hline Rata-Rata & 84,7 & 76,5 \\
\hline SD & 85 & 76,10 \\
\hline SD & & \\
\hline
\end{tabular}

Berdasarkan tabel 2 kemampuan motorik kasar pada post-test di kelas eksperimen dan kontrol, diperoleh hasil kemampuan motorik kasar anak dikelas 
Volume 6, Nomor 1, April 2019, hal 29 - 34

eksperimen lebih tinggi di bandingkan kelas kontrol. Agar lebih jelas dapat kita lihat pada tabel berikut.

Dilihat dari hasil uji hipotesis dengan menggunakan t-test diperoleh hasil sebagaimana disajikan dalam tabel 3. Dari tabel 3 berikut diketahui dengan taraf $\alpha=$ $0,05, \mathrm{dk}=18$ dimana $(\mathrm{N} 1-1)+(\mathrm{N} 2-1)$ yaitu : 2,100 dapat diketahui $t_{\text {hitung }}<$ dari $t_{\text {tabel }}$ $[1,497<2,100]$. Oleh sebab itu, dikatakan hipotesis $\mathrm{H}_{\mathrm{a}}$ ditolak atau $\mathrm{H}_{\mathrm{o}}$ diterima. Sehingga, dapat disimpulkan bahwa terdapatnya perbedaan signifikan antara hasil pre-test anak kelas eksperimen dan kelas kontrol dalam pengembangan motorik kasar.

Dari tabel 4 berikut dengan taraf signifikansi $\alpha=0,05, \mathrm{dk}=18$ dimana (N11)+(N2-1) diperoleh nilai $t_{\text {tabel }}$ yaitu : 2,100 dapat diketahui $t_{\text {hitung }}>$ dari $t_{\text {tabel }}[2,279>2,100]$ oleh sebab itu dikatakan hipotesis $\mathrm{H}_{\mathrm{o}}$ ditolak atau $\mathrm{H}_{\mathrm{a}}$ diterima. Sehingga dapat disimpulkan bahwa terdapatnya perbedaan signifikan antara hasil pre-test anak kelas eksperimen dan kelas kontrol dalam pengembangan motorik kasar. Dari data yang sudah diolah dapat disimpulkan bahwa tari ayam modifikasi berpegaruh terhadap perkembangan motorik kasar anak dibandingkan dengan senam. Untuk lebih jelasnya dapat dilihat dari grafik 1 .

Tabel 3. Hasil Perhitungan Pre-Test Pengujian dengan t-test

\begin{tabular}{clccccc}
\hline $\begin{array}{c}\mathbf{N} \\
\mathbf{0}\end{array}$ & Kelompok & $\mathbf{N}$ & $\begin{array}{c}\text { Rata- } \\
\text { rata }\end{array}$ & $\boldsymbol{t}_{\text {hitung }}$ & $\boldsymbol{t}_{\text {tabel }}$ & $\begin{array}{c}\text { Keputu } \\
\text { san }\end{array}$ \\
& & & & & & \\
\hline $\mathbf{1}$ & Eksperimen & 10 & 64,5 & 1,497 & 2,10 & Terima \\
& Kontrol & 10 & 59,5 & & 0 & Ho
\end{tabular}

Tabel 4. Hasil Perhitungan Post-Test Pengujian dengan t-test

\begin{tabular}{lllllll}
$\begin{array}{l}\mathbf{N} \\
\mathbf{0}\end{array}$ & Kelompok & $\mathbf{N}$ & $\begin{array}{c}\text { Rata- } \\
\text { rata }\end{array}$ & $\boldsymbol{t}_{\text {hitung }}$ & $\boldsymbol{t}_{\text {tabel }}$ & $\begin{array}{l}\text { Keputu } \\
\text { san }\end{array}$ \\
\cline { 1 - 4 } $\mathbf{1}$ & Eksperimen & 10 & 85 & 2,279 & $\begin{array}{l}2,10 \\
0\end{array}$ & $\begin{array}{l}\text { Ho } \\
\text { ditolak }\end{array}$
\end{tabular}

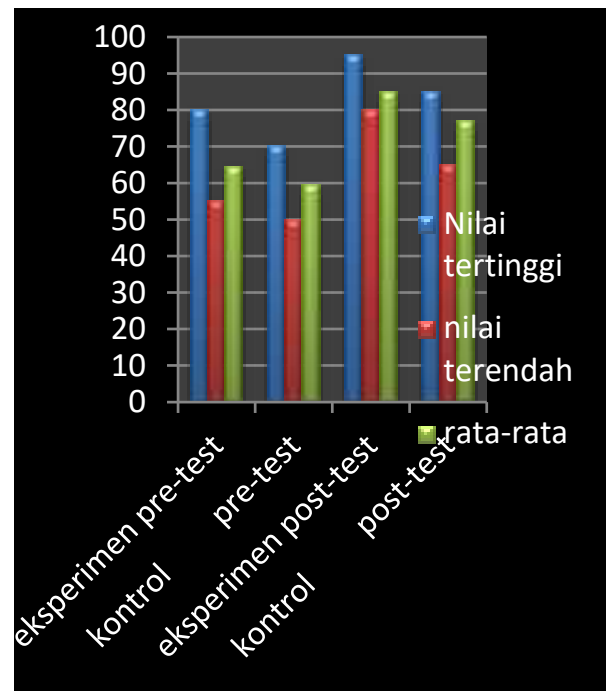

Grafik 1. Hasil Perbandingan Data PreTest dan Post-Test Motorik Kasar Anak Kelas Eksperimen Melalui Tari Ayam Modifikasi dan Kelas Kontrol Melalui Senam

Dari penjelasan diatas, perkembangan kemampuan motorik kasar pada anak terlihat pada hasil kelas eksperimen B1 jauh lebih baik dari perkembangang motorik kasar anak di kelas kontrol B2. Ini dapat dilihat dari nilai yang sudah diolah sehingga terdapat rata-rata anak kelas eksperimen lebih tinggi dari pada kelas kontrol.

\section{Pembahasan}

Terlebih dahulu sebelum melakukan penelitian peneliti membuat kisi-kisi instrument sebagai pedoman penilaian perkembangan motorik kasar anak. Kisikisi intrumen ini telah divalidatori oleh dosen ahli. Peneliti menguji kevalidan dari kisi-kisi tersebut di TK Plus Marhamah Padang. Setelah data didapatkan peneliti langsung melakukan uji validitas dan uji reabilitas untuk mengetahui apakah kisi-kisi akurat dan dapat dipertanggung jawabkan. Peneliti menggunakan 5 item pernyataan yang telah diuji kevalidan dan reliabelnya dalam menilai perkembangan motorik kasar anak di TK Jabal Rahmah Padang.

Gallahue dalam (Mirantika 2017: 3) kegiatan menari, permainan, olahraga, dan senam merupakan kegiatan dalam mengembangkan pola-pola gerak karena termasuk ke dalam pengembangan motorik. Sehingga kebutuhan dasar anak terarah kaarah yang benar. 
Modifikasi tari adalah kegiatan mengubah, menambah, mempercantik gerakan tari sehingga lebih enak dipandang. Mengubah ruang, tenaga dan arah hadap termasuk kedalam memodifikasi gerak yang kita rangkai sendiri sehingga menghasilkan sebuah tari. Harry dalam (Gusti 2018:29).

Masganti (2017: 8) animal dance tari yang sangat cocok dengan karakteristik anak usia dini yaitu tarian yang sederhana yang mudah dipahami anak dengan musik kegembiraan sehingga anak tertarik dan anak bersemangat dalam menggerakkan anggota tubuhnya.

Setelah dilakukan treatment dengan menggunakan tari ayam modifikasi pada kelas eksperimen tersebut dilakukan dengan kegiatan yang mengembirakan dan tidak membosankan karena dengan tari ayam modifikasi dapat membuat anak bergerak bebas menari diiringi musik gembira.

Sedangkan pada kelas kontrol anak tidak bersemangat dalam melakukan senam, pada saat penelitian terlihat perbedaan antara kedua kelas eksperimen dan kelas kontrol terkait dengan keantusiasan dalam pembelajaran, pada kelas eksperimen menggunakan tari ayam modifikasi, anak sangat antusias dalam menarikan tari ayam modifikasi karena gerakkannya energik dan diiringi oleh musik gembira, masing-masing anak diberikan topi kepala ayam dan pernakpernik ayam agar anak mengetahui bagian dari ayam. Sedangkan kelas kontrol (B2) menggunakan senam yang biasa digunakan guru dalam mengembangkan motorik kasar anak. Senam dilakukan 1 kali dalam seminggu dan gerakannya hanya itu saja. Jadi, anak kurang antusias dalam melakukan senam.

Dengan demikian hasil perkembangan kemampuan motorik kasar anak kelas eksperimen B1, lebih baik dibandingkan anak kelas kontrol B2. Maka dapat disimpulkan terdapat pengeruh signifikan terhadap kemampuan motorik kasar anak di TK Jabal Rahmah Padang.

\section{SIMPULAN}

Penelitian yang dilakukan di TK Jabal Rahmah Padang, dapat disimpulkan : nilai kelas eksperimen ditemukan nilai lebih tinggi dengan rata-rata 85 dengan tari ayam modifikasi dibandingkan dengan kelas kontrol dengan rata-rata 77 dengan senam.

Berdasarkan uji signifikan pada taraf $\alpha=0,05$ dan $\mathrm{dk}=18$ ditemukan $\mathrm{H}_{\mathrm{a}} 2,279$ pada nilai tabel 2,100. Sehingga terbukti berpengaruh. Jadi, dapat disimpulkan bahwa tari ayam modifikasi berpengaruh dalam mengembangkan kemam puan motorik kasar anak di Taman KanakKanak Jabal Rahmah Padang.

\section{SARAN}

Kepada guru Taman Kanak-Kanak Jabal Rahmah padang agar kegiatan tari ayam modifikasi dapat dijadikan alternatif dalam melihat perkembangan lebih lanjut pada anak dan dalam mengembangkan motorik kasar anak. Sebaiknya, guru merancang kegiatan dan menggunakan media yang lebih bervariasi kepada anak. Selain itu saya berharap kepada peneliti selanjutnya penelitian ini untuk menjadi panutan dalam melakukan penelitian yang akan datang. Dan terakhir saya berharap agar motorik kasar anak berkembang melalui tari ayam modifikasi ini.

\section{DAFTAR PUSTAKA}

Astuti, F. (2016). Pengetahuan \& Teknik Menata Tari Untuk Anak Usia Dini. Jakarta: Rineka Cipta

Gusti, R. Y. (2018). Pengaruh Tari Kelinci Terhadap Perkembangan Motorik Kasar Anak di Taman KanakKanak Habibi Padang Pariaman. Skripsi. Tidak diterbitkan. Padang: UNP

Marlina, S. (2014). Peningkatan Sikap Sosial Anak Usia Dini Melalui Permainan Puzzle Buah Di Taman Kanak-Kanak Aisyiyah Bukittinggi. PEDAGOGI Jurnal Ilmiah Ilmu Pendidikan. Volume XIV Nomor 2 November 2014 (diakses pada tanggal 24 mei 2019)

Masganti, M. (2017). Upaya Meningkatkan Kemampuan Motorik Kasar Anak Usia 5-6 Tahun Melalui Kegiatan 
34 Jurnal PG-PAUD Trunojoyo : Jurnal Pendidikan dan Pembelajaran Anak Usia Dini,

Volume 6, Nomor 1, April 2019, hal 29 - 34

Menari Animal Chicken Dance.

Jurnal Tarbiyah, Volume 05 (02);

Juli-Desember 2017,

https://jurnaltarbiyah.uinsu.ac.id

(diakses pada tanggal 15 Januari

2019 pukul 21:32)

Mirantika,

D.

(2017).

Upaya Meningkatkan Kemampuan

Motorik Kasar Anak Usia 5-6 Tahun

Melalui Kegiatan Menari

Tari Animal Chicken Dance. Jurnal

Tarbiyah, Vol. 05, No. 02 Juli-

Desember 2017,

http://jurnaltarbiyah.uinsu.ac.id

(diakses pada tanggal 15 januari

2019 pukul 21:32)

Mursid. (2015). Belajar dan Pembelajaran

PAUD. Bandung: Remaja

Rosdakarya

Mulyani, N. (2016). Pendidikan Seni Tari Anak Usia Dini. Yogyakarta: Gava Media

Nurhafizah \& Kosnin, A. M. (2015). Implementasi Permainan Tradisioanal Indonesia di Taman Kanak-Kanak Kota Padang. Jurnal Ilmiah Ilmu Pendidikan. Volume XV No .1 April 2015 (diakses pada tanggal 24 Mei 2019)

Nurhafiza \& R.Yetti. (2018). Implementation of Children Kinesthetic Intelligence Development Activities in Kindergarten. Jurnal Penelitian Pendidikan Indonesia. Volume 4 Nomor 2, 30 Desember 2018. (diakses pada tanggal 24 Mei 2019)

Suryana, D. (2016). Pendidikan Anak Usia Dini Stimulasi \& Aspek Perkembangan Anak. Jakarta: Kencana.

Yenni, I. (2010). Perkembangan Instrumentasi dan Lagu Talempong Kreasi di Sumatra Barat. Jurnal Bahasa dan Seni. Vol 11 Nomor 2 tahun 2010 (diakses pada tanggal 24 Mei 2019) 